\title{
Proteomics of Bordetella pertussis whole-cell and acellular vaccines
}

\author{
Jens Möller ${ }^{1}$, Max Edmund Kraner ${ }^{2}$ and Andreas Burkovski ${ }^{1 *}$ (B)
}

\begin{abstract}
Objectives: Bordetella pertussis is the etiological agent of whooping cough, a bacterial infection of especially children, which may be fatal without treatment. In frame of studies to investigate putative effects of vaccination on hostpathogen interaction and clonal distribution of strains, in addition to Corynebacterium diphtheriae and Clostridium tetani toxoid vaccines, also whole-cell and acellular pertussis vaccines were analyzed by mass spectrometry.

Data description: LC-MS/MS spectra were generated and analyzed using B. pertussis genome data and proteins present in whole-cell and acellular pertussis vaccines were identified. Subcellular localization of proteins and presence of signal peptides was determined bioinformatically.
\end{abstract}

Keywords: Bordetella, DTP vaccine, LC-MS/MS, Mass spectrometry, Pertussis, Vaccination, Whooping cough

\section{Objective}

Bordetella pertussis is the etiological agent of whooping cough, a bacterial infection of especially children, which may be fatal without treatment. In 2008 about 16 million cases of whooping cough-also designated as pertussisresulting in almost 200,000 pediatric deaths were estimated by the World Health Organization, while for 2015 more than 60,000 deaths of infants were assumed [1-3]. These numbers of worldwide cases illustrate that pertussis is a continuing threat to children's health and vaccination is important to prevent this infection. In frame of studies to investigate putative effects of vaccination on host-pathogen interaction and clonal distribution of strains, in addition to Corynebacterium diphtheriae [4] and Clostridium tetani [5] toxoid vaccines, also pertussis vaccines were analyzed by mass spectrometry (MS). In order to identify putative immunogenic proteins and to provide data to understand the influence of vaccination on the distribution of B. pertussis strains, two different types of vaccines were analyzed in respect to their protein content: a whole-cellular and an acellular pertussis vaccine. Whole-cell vaccines are suspensions of killed

\footnotetext{
*Correspondence: andreas.burkovski@fau.de

${ }^{1}$ Friedrich-Alexander-Universität Erlangen-Nürnberg, Staudtstr. 5, 91058 Erlangen, Germany

Full list of author information is available at the end of the article
}

B. pertussis cells, while the acellular pertussis vaccines, which were developed to prevent unwanted local reactions of the whole-cell vaccine, contain only a limited number of purified components (for overview of different vaccine formulations see [3]. An influence of vaccination strategy used and components included in the vaccine on evolution of $B$. pertussis strains in human populations was already discussed $[6,7]$, based on an observed effect of vaccination on the distribution of different alleles in $B$. pertussis. For example, the pertactin-encoding prn 1 allele was dominating in the pre-vaccine era, while after introduction of the whole-cellular vaccine produced with a prn1-carrying strain, B. pertussis isolates harboring the prn2 allele increased [8]. Also a change in the fimbrial serotype of $B$. pertussis strains was observed from serotype Fim 2 predominantly found in unvaccinated populations to serotype Fim 3 and serotype Fim2,3 in vaccinated populations [9]. Since proteome analyses of $B$. pertussis and corresponding vaccines are scarce [10], the proteomics data presented in this data note may be helpful for further evolutionary studies.

\section{Data description}

The data represent proteomic analyses of commercially vaccines, an acellular and a whole cellular pertussis vaccine. Raw data files (.raw), MS/MS spectra files (.msf), 
Table 1 Overview of data files/data sets

\begin{tabular}{|c|c|c|c|}
\hline Label & Name of data file/data set & File types (file extension) & $\begin{array}{l}\text { Data repository and identifier (DOI } \\
\text { or accession number) }\end{array}$ \\
\hline Data set 1 [15] & Bordetella pertussis vaccine project & $\begin{array}{l}\text { RAW data file (.raw), MS/MS spectra files } \\
\text { (.msf), MS Excel file (.xlsx), peptide } \\
\text { sequence assignment files (pep.xml) }\end{array}$ & $\begin{array}{l}\text { http://identifiers.org/pride.project:PXD01 } \\
3804\end{array}$ \\
\hline Data set 2 [16] & Results table & MS Excel file (.xIsx) & https://doi.org/10.6084/m9.figshare.8108165 \\
\hline Data set 3 [17] & $\begin{array}{l}\text { Images of Bordetella pertussis vaccine } \\
\text { analysis }\end{array}$ & PDF (.pdf) & https://doi.org/10.6084/m9.figshare.8108210 \\
\hline
\end{tabular}

peptide sequence assignment files of MS/MS scans (pep. $\mathrm{xml}$ ) as well as a list of identified proteins (.xlsx) were deposited to the ProteomeXchange Consortium (http:// proteomecentral.proteomexchange.org) via the PRIDE partner repository [11] and are available with identifier PXD013804 (Table 1). The data set provided includes a table with identified proteins in the analyzed vaccines, their molecular function and cellular localization as well as a PDF file containing three images depicting these results, a list with vaccines used in this study and a table with identified proteins related to pathogenicity (Table 1).

\section{Methodology \\ Protein sample preparation}

Bordetella pertussis vaccines are typically administered in combination with diphtheria and tetanus toxoid vaccines as DTP3 vaccines. In this study, we analyzed one acellular and one whole cellular commercially available pertussis vaccine (for details, see Data set 1 ). The sample preparation of the vaccines for mass spectrometry analysis was carried out as described recently $[4,5]$. In short, the proteins were transferred to $10 \mathrm{kDa}$ membrane filters and processed using a modified protocol for Filter Aided Sample Preparation (FASP) [12, 13]. After filter-based tryptic digest and elution, the peptides were desalted and concentrated using $\mathrm{C} 18$ stage tips. Prior to LC-MS/MS (liquid chromatography tandem-mass spectrometry), peptides were vacuum dried and solved in $0.1 \%$ trifluoroacetic acid (TFA) [14].

\section{Mass spectrometry and data analysis}

Mass spectrometric analyses were carried out as described before $[4,5,13,14]$ using a combination of a nanoflow Ultimate 3000 HPLC (Dionex, Sunnyvale, CA, USA) and an Orbitrap Fusion mass spectrometer (Thermo Fisher Scientific, Waltham, MA, USA). Resulting raw data files were analyzed using the $C$. diphtheriae ATCC 700971/NCTC 13129/Biotype gravis database (Proteome Id: UP000002198), the Clostridium tetani E88 database, (Proteome Id: UP000001412) and the Bordetella pertussis (strain Tohama I/ATCC BAA-589/NCTC
13251) database (Proteome Id.: UP000002676) using the Proteome Discoverer 1.4 program package (Thermo Fisher Scientific, Bremen, Germany). Identification of product ions was carried out as described recently [4, 5]: theoretical peptide masses for trypsin digestion were generated allowing two missed cleavages and the following settings were used for analysis: (i) carbamidomethyl modification of cysteine residues fixed, (ii) oxidation of methionine dynamic, (iii) mass tolerance $10 \mathrm{ppm}$ for survey scans, (iv) $0.6 \mathrm{Da}$ for fragment mass measurements, (v) protein identification threshold $1 \%$ false discovery rate (FDR).

In total 1855 unique proteins were identified by mass spectrometry analyses with 1850 distinct proteins identified in the whole cellular vaccine and 25 unique identified in the acellular vaccine.

\section{Limitations}

The data presented here were obtained in frame of a project focusing on diphtheria and tetanus toxoid vaccines. Since these vaccines are administered in different combinations, only part of the samples contained $B$. pertussis proteins and the number of pertussis vaccines was limited to three.

\section{Abbreviations}

FASP: Filter Aided Sample Preparation; FDR: false discovery rate; LC-MS/MS: liquid chromatography tandem-mass spectrometry; MS: mass spectrometry; TFA: trifluoroacetic acid; WHO: World Health Organization.

\section{Acknowledgements}

The study was supported by the Deutsche Forschungsgemeinschaft in frame of SFB796 (project B6 and Z1). Vaccines were kindly provided A. L. MattosGuaraldi (Rio de Janeiro State University, Rio de Janeiro, Brazil).

\section{Authors' contributions}

Protein preparation, data analysis and visualization of results was carried out by JM; MEK carried out mass spectrometry analyses and was responsible for data storage; conceptualization, supervision of experiments; writing of the draft as well as project administration was carried out by AB. All authors read and approved the manuscript.

\section{Funding}

This research received no external funding. 


\section{Availability of data materials}

The data described in this Data note can be freely and openly accessed on (http://proteomecentral.proteomexchange.org) via the PRIDE partner repository and (https://figshare.com/). Please see Table 1 and reference list [15-17] for details and links to the data.

\section{Ethics approval and consent to participate}

Not applicable.

\section{Consent for publication}

Not applicable.

\section{Competing interests}

The authors declare that they have no competing interests.

\section{Author details}

${ }^{1}$ Friedrich-Alexander-Universität Erlangen-Nürnberg, Staudtstr. 5, 91058 Erlangen, Germany. ${ }^{2}$ Lehrstuhl für Biochemie, Friedrich-Alexander-Universität Erlangen-Nürnberg, Erlangen, Germany.

Received: 20 May 2019 Accepted: 5 June 2019

Published online: 10 June 2019

\section{References}

1. World Health Organization. Immunization, vaccines and biologicals: pertussis. http://www.cdc.gov/pertussis/surv-reporting/cases-by-year html. Accessed 20 May 2019

2. World Health Organization. Immunization, vaccines and biologicals: pertussis. http://www.who.int/immunization/topics/pertussis/en/index .html. Accessed 20 May 2019.

3. Edwards KM, Decker MD. Pertussis toxin. Plotkin's vaccines. Amsterdam: Elsevier; 2018. p. 711-61.

4. Möller J, Kraner M, Sonnewald U, Sangal V, Tittlbach H, Winkler J, Winkler TH, Melnikov V, Lang R, Sing A, Mattos-Guaraldi A-L, Burkovski A. Proteomics of diphtheria toxoid vaccines reveals multiple proteins that are immunogenic and may contribute to protection of humans against Corynebacterium diphtheriae. Vaccine. 2019;37:3061-70.

5. Möller J, Kraner ME, Burkovski A. More than a toxin: protein inventory of Clostridium tetani toxoid vaccines. Proteomes. 2019;7:15.

6. Mooi FR, Van Loo IHM, King AJ. Adaptation of Bordetella pertussis to vaccination: a cause for its reemergence? Emerg Infect Dis. 2001;7:526-8.
7. Zhang L, Xu Y, Zhao J, Kallonen T, Cui S, Xu Y, Hou Q, Li F, Wang J, He Q, Zhang S. Effect of vaccination on Bordetella pertussis strains, China. Emerg Infect Dis. 2010;16:1695-701.

8. Xu Y, Liu B, Gröndahl-Yli-Hannuksila K, Tan Y, Feng L, Kallonen T, Wang $L$, Peng $D$, He Q, Wang $L$, Zhang S. Whole-genome sequencing reveals the effect of vaccination on the evolution of Bordetella pertussis. Sci Rep. 2015;5:1-10.

9. Hallander HO, Advani A, Donnelly D, Gustafsson L. Shifts of Bordetella pertussis variants in Sweden from 1970 to 2003, during three periods marked by different vaccination programs. J Clin Microbiol. 2005;43:2856-65.

10. Raeven $\mathrm{RH}$, van der Maas L, Tilstra W, Uittenbogaard JP, Bindels TH, Kuipers B, van der Ark A, Pennings JL, van Riet E, Jiskoot W, Kersten GF, Metz B. Immunoproteomic profiling of Bordetella pertussis outer membrane vesicle vaccine reveals broad and balanced humoral immunogenicity. J Proteome Res. 2015;14:2929-42.

11. Vizcaíno JA, Csordas A, Del-Toro N, Dianes JA, Griss J, Lavidas I, Mayer G, Perez-Riverol Y, Reisinger F, Ternent T, Xu QW, Wang R, Hermjakob H. 2016 update of the PRIDE database and its related tools. Nucleic Acids Res. 2016:44:D447-56

12. Wisniewski JR, Zougman A, Nagaraj N, Mann M. Universal sample preparation method for proteome analysis. Nat Methods. 2009;6:359-62.

13. Kraner ME, Müller C, Sonnewald U. Comparative proteomic profiling of the choline transporter-like1 (CHER1) mutant provides insights into plasmodesmata composition of fully developed Arabidopsis thaliana leaves. Plant J. 2017;92:696-709.

14. Bittel M, Gastiger S, Amin B, Hofmann J, Burkovski A. Surface and extracellular proteome of the emerging pathogen Corynebacterium ulcerans. Proteomes. 2018;6:18

15. Möller J, Kraner ME, Burkovski A. Proteomics of Bordetella pertussis wholecell and acellular vaccines. ProteomeXchange Consortium. http://ident ifiers.org/pride.project:PXD013804. 2019.

16. Möller J, Kraner ME, Burkovski A. Data set 2_Results table. figshare. https //doi.org/10.6084/m9.figshare.8108165.2019.

17. Möller J, Kraner ME, Burkovski A. Data set 3. figshare. https://doi org/10.6084/m9.figshare.8108210. 2019.

\section{Publisher's Note}

Springer Nature remains neutral with regard to jurisdictional claims in published maps and institutional affiliations.

Ready to submit your research? Choose BMC and benefit from:

- fast, convenient online submission

- thorough peer review by experienced researchers in your field

- rapid publication on acceptance

- support for research data, including large and complex data types

- gold Open Access which fosters wider collaboration and increased citations

- maximum visibility for your research: over $100 \mathrm{M}$ website views per year

At $\mathrm{BMC}$, research is always in progress.

Learn more biomedcentral.com/submissions 